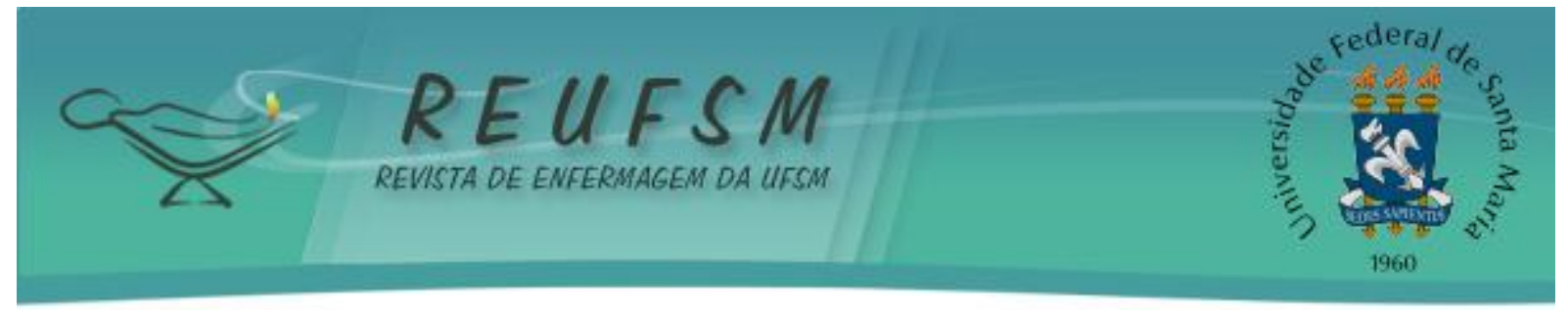

ARTIGO ORIGINAL

\title{
DESAFIOS NA CONSTRUÇÃO DE UM PROJETO DE EDUCAÇÃO PERMANENTE EM SAÚDE
}

\section{CHALLENGES IN THE CONSTRUCTION OF A PROJECT IN PERMANENT EDUCATION IN HEALTH \\ DESAFÍOS EN LA CONSTRUCCIÓN DE UN PROYECTO DE EDUCACIÓN PERMANENTE EN SALUD}

\author{
Luiz Anildo Anacleto da Silva ${ }^{1}$ \\ Daiane Michele Bonacina ${ }^{2}$ \\ Andressa de Andrade ${ }^{3}$ \\ Thanyze Carvalho de Oliveira ${ }^{4}$
}

RESUMO: Objetivo: conhecer os desafios encontrados na construção de uma proposta de Educação Permanente em Saúde em uma instituição hospitalar. Método: o estudo caracteriza-se como uma pesquisa qualitativa, descritiva e exploratória. Os sujeitos foram membros da equipe multiprofissional em saúde. Resultados: os resultados indicam que, apesar das dificuldades que se tem para a implementação de uma proposta de educação institucional, a equipe multiprofissional reconhece sua importância para a qualificação dos profissionais e da assistência. Considerações finais: os desafios constam a superação da cultura tecnicista de educação, da burocracia, assim como a integralização da educação no processo de trabalho.

Descritores: Educação em saúde; Instituições de saúde; Recursos humanos e serviços; Planejamento de instituições de saúde; Recursos humanos em saúde.

ABSTRACT: Objective: to meet the challenges in building a proposal for continue education in health in hospital institution. Method: the study is characterized as a qualitative, descriptive and exploratory. The study subjects were members of the multidisciplinary team. Results: the results indicate that, despite the difficulties to implement a proposal for institutional education, multidisciplinary team recognizes its importance to the highest professional qualification and qualification of care. Conclusion: the challenges included: overcoming the culture technicist education, bureaucracy and the payment of education in the work process.

Descriptors: Health education; Health care facilities; Manpower, and services; Planning of health institutions; Health manpower.

RESUMEN: Objetivo: conocer los desafíos en la elaboración de una propuesta de Educación permanente en Salud en un hospital. Método: el estudio se caracteriza por ser de carácter cualitativo, descriptivo y exploratorio. Los sujetos del eran miembros del equipo multiprofesional de salud. Resultados: los resultados indican que, a pesar de las dificultades que tienen para poner en práctica una propuesta de educación institucional, el equipo multiprofesional reconoce su importancia para una mayor cualificación profesional y de la

\footnotetext{
${ }^{1}$ Enfermeiro. Doutor em Enfermagem. Docente do Curso de Enfermagem do Centro de Educação Superior Norte do Estado do Rio Grande do Sul - Universidade Federal de Santa Maria. Email: luiz.anildo@yahoo.com.br luiz.anildo@smail.ufsm.br

${ }^{2}$ Enfermeira graduada no Centro de Educação Superior Norte do Estado do Rio Grande do Sul - Universidade Federal de Santa Maria. Email: daiabonacina@yahoo.com.br

${ }^{3}$ Enfermeira. Mestre em Ciências da Saúde. Docente do Curso de Enfermagem do Centro de Educação Superior Norte do Estado do Rio Grande do Sul - Universidade Federal de Santa Maria. Email: andressaufsm@gmail.com ${ }^{4}$ Enfermeira da Unidade de Terapia Intensiva do Hospital de Caridade de Três Passos. Especialista em Urgência e Emergência. Email: thanyze@yahoo.com.br
} 


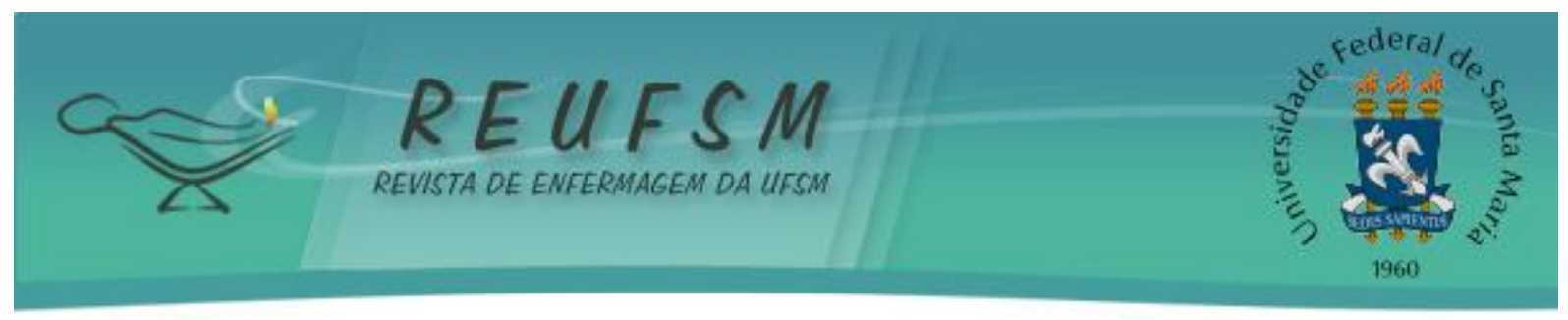

atención. Conclusión: los retos incluyen: la superación de la cultura de la educación tecnicista, la burocracia y la integración de la educación en el proceso de trabajo.

Descriptores: Educación en salud; Instituciones de salud; Recursos humanos y servicios; Planificación de instituciones de salud; Recursos humanos en salud.

\section{INTRODUÇÃO}

A implementação de ações de educação no trabalho, constitui-se em um dos mais sérios desafios para os gestores/trabalhadores dos serviços de saúde. No estudo ora apresentado, trata dos desafios que são encontrados na construção de uma proposta de Educação Permanente em Saúde (EPS) para a equipe multiprofissional de um hospital de médio porte em um município do interior do estado do Rio Grande do Sul. Na educação no trabalho, parte-se do princípio de que o processo educativo possa transpassar-se com as atividades do cotidiano dos sujeitos, pois se preconiza uma ação educativa dialógica e interativa e que permite aos sujeitos serem protagonistas do seu processo educativo, pois a dinamicidade do processo permite aos sujeitos ora serem educandos ora educadores. ${ }^{1}$

Considera-se a educação um fenômeno social e universal, bem como uma atividade necessária para o desenvolvimento humano. No entanto, para que isso aconteça, necessita-se investir na contínua educação dos sujeitos, ajudando-os no desenvolvimento de suas capacidades, para que possam tornar-se mais ativos nas instâncias sociais em que convivem. A educação não é apenas uma exigência da vida em sociedade, mas também é o processo para prover os sujeitos de conhecimentos, articulados com experiências culturais, científicas, éticas que os tornem capazes de interagir e contribuir no meio social em que convivem. As transformações efetivamente dependem da intersecção, entre fazeres e saberes. É nesta perspectiva que a EPS advém de uma nova política para formação de recursos humanos em saúde. ${ }^{2}$

A EPS pode proporcionar aos sujeitos uma forma diferenciada de aprendizado, que inclui a troca de saberes/fazeres com a intersecção entre o preceito teórico e a reflexão das práticas diárias, na qual a teoria subsidia a prática e a prática fundamenta a teoria, continuamente realimentando-se e interativamente construindo novos conhecimentos, sedimentando-os, de acordo com as necessidades pessoais e institucionais. A EPS utiliza-se de estratégias que buscam a reflexão crítica sobre as práticas de serviço, sendo, por si só, uma prática educativa aplicada ao/no trabalho que possibilita transformações nas relações, nos processos de trabalho, nas condutas, nas atitudes, nos profissionais e na equipe. ${ }^{3}$ A EPS constitui-se em uma política de estado, a qual visa, entre tantos objetivos, a participação e a construção de propostas de qualificação dos trabalhadores como forma de consolidação do Sistema Único de Saúde (SUS). ${ }^{4}$

A política de EPS, proposta pelo Ministério da Saúde, procura integralizar o processo educativo, ao assegurar a participação de vários segmentos sociais, em especial, os prestadores dos serviços, usuários, instituições de ensino e movimentos sociais, estabelecendo-se como objetivo primordial o fortalecimento e a consolidação do SUS. Nesta proposta, parte-se dos princípios que orientam este sistema, ou seja, a construção descentralizada, a universalidade, a integralidade, e a participação popular. ${ }^{4}$

Parte-se do entendimento que a EPS possa contribuir para melhorar a formação profissional e, em contrapartida, fortalecer o SUS, assim como, assegurar o desenvolvimento dos trabalhadores e das instituições de saúde e contribuir na gestão dos sistemas e serviços. ${ }^{5}$ Entre os desafios atinentes a EPS constam a superação ao tecnicismo, o estímulo à reflexão e à conscientização dos profissionais sobre o seu contexto. Dessa forma, o processo educativo pode ser assumido como passaporte para a transformação, transcendendo a condição de sujeito passivo, ao papel de protagonista no processo educativo. ${ }^{6}$ 


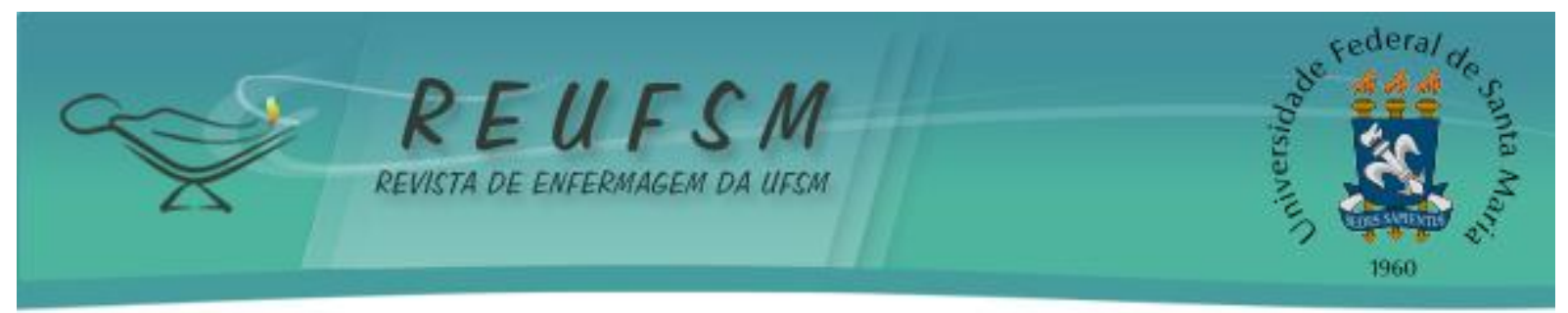

A proposta de EPS do Ministério da Saúde (MS) contrapõe-se ao conceito de educação continuada, a qual tem como prerrogativa as capacitações pós formação inicial, com o objetivo de estruturação e desenvolvimento dos serviços de saúde. Já com a EPS, procura-se manter o vínculo entre formação e exercício profissional, através da adoção de novas metodologias de ensino/aprendizagem, em especial, a problematização e a aprendizagem significativa. Projeta-se também que a EPS possa ser uma estratégia de transformação na formação/ensino e de gestão dos serviços de saúde, promovendo mudanças na atenção, na formulação de políticas e de controle social. ${ }^{7}$

Pressupõe-se que a estruturação de uma proposta de educação permanente institucional possa constituir-se em uma das alternativas de rever e (re)significar o processo de trabalho, em razão de que os preceitos educativos constituem-se em uma das formas de qualificação dos trabalhadores em saúde e a consequente oferta de uma assistência mais resolutiva.

O estudo se justifica na razão que se entende, que a apropriação de conhecimentos teórico-práticos por parte dos trabalhadores, está intrinsecamente vinculada à qualificação da assistência aos usuários e, por conseguinte, que a educação aos trabalhadores da saúde constitui-se em uma das mais importantes estratégias na consolidação dos princípios do SUS. Para tanto, estabeleceu-se como questão de pesquisa: quais os desafios que se interpõem na construção de uma proposta de educação permanente em saúde para a equipe multiprofissional de um hospital de médio porte de um município na região noroeste do Rio Grande do Sul?

Em razão do exposto, objetivou-se conhecer os desafios encontrados na construção de uma proposta de Educação Permanente em Saúde em uma instituição hospitalar.

\section{MÉTODO}

Esta pesquisa é de caráter qualitativo, descritivo e exploratório. ${ }^{8}$ Utilizou-se como instrumento de pesquisa a entrevista semiestruturada. ${ }^{9}$ Os sujeitos da pesquisa foram trabalhadores da equipe multiprofissional, os quais são identificados pelos códigos $(\mathrm{E} 1,2,3 \ldots)$ para enfermeiros(as), (N1...) para nutricionistas, $(\mathrm{M} 1,2 \ldots)$ para médicos, (AS 1...) para assistentes sociais, ( $F 1 .$.$) para farmacêuticos e (P1...) para psicólogas.$ Incluíram-se os sujeitos que tinham mais de dois anos de atuação profissional na instituição. Excluíram-se aquelas profissões que tivessem somente um profissional na área de atuação. Os dados foram coletados entre os meses de agosto e outubro de 2011.

A definição dos sujeitos deu-se pelo sistema de amostra proposital, intencional ou deliberada. ${ }^{10} \mathrm{Na}$ definição da população do estudo, procurou-se entrevistar sujeitos de cada categoria profissional e de diferentes áreas de atuação. No estudo, observaram-se rigorosamente os preceitos éticos em conformidade com o que prevê a Resolução do Conselho Nacional de Saúde/Portaria 196/96. ${ }^{11}$ Participaram os sujeitos que, de livre e espontânea vontade, após terem o conhecimento do projeto, assinaram o Termo de Consentimento Livre e Esclarecido (TCLE), concordando em fazer parte do estudo. 0 projeto foi submetido à apreciação do Comitê de Ética em Pesquisa da Universidade Federal de Santa Maria em 07 de julho de 2011, conforme consta no processo de $\mathrm{n}^{\circ}$ 23081.007733/2011-8.

\section{RESULTADOS E DISCUSSÃO}

A apreciação dos dados foi realizada pela proposta de análise temática ${ }^{12}$, a qual permitiu a construção de três categorias e subcategorias: a primeira categoria refere-se 


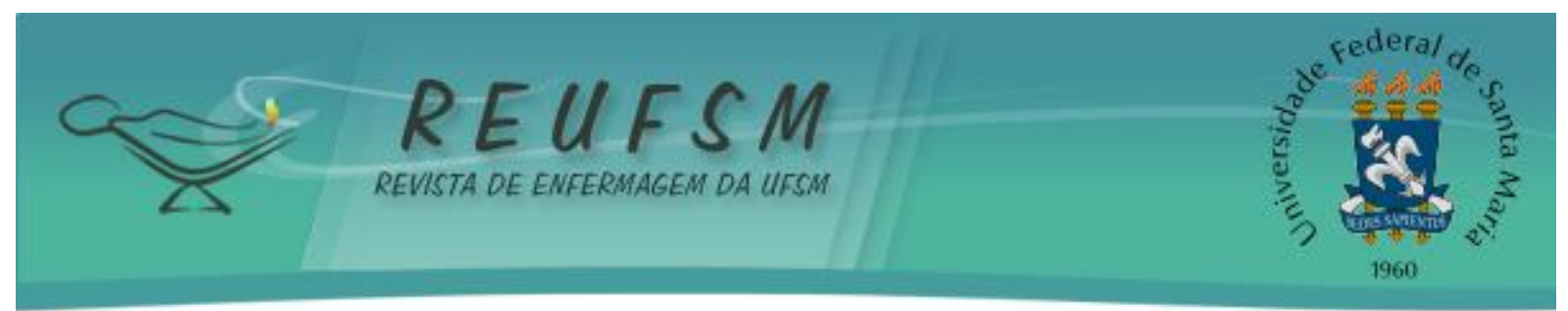

aos 'fatores que facilitam a construção de uma proposta de educação permanente em saúde', dividida nas subcategorias 'organização do trabalho' e a disponibilização de 'cursos extras institucionais', na segunda categoria descrevem-se os 'fatores limitadores na construção de uma proposta de Educação Permanente em Saúde'; e a terceira e última categoria a questão da 'organização de uma proposta de Educação Permanente em Saúde'; dividida nas subcategorias 'processo de EPS como estratégia para qualificar os serviços' e 'EPS no contexto institucional'.

\section{Os fatores que facilitam a construção de propostas educativas}

A organização do trabalho pode ser entendida como um processo que envolve as atividades dos trabalhadores, as relações de trabalho com seus pares, equipe multiprofissional, hierarquia e, que ocorre numa determinada estrutura institucional. A forma de organização no trabalho sofre influências estruturais, bem como a forma de gestão empreendida pela instituição, que, por sua vez, atrela-se ao modo de produção vigente.

[...] as necessidades contínuas de obtenção de conhecimentos $e$ viabilização de propostas educativas. (E1)

A construção de propostas de educação em saúde precisa estar articulada com as necessidades dos sujeitos, sejam esses, trabalhadores e/ou usuários. Essa forma de organização permite que as ações educativas sejam profícuas e possam efetivamente impactar em mudanças no processo de trabalho.

[...] acredita que um dos fatores que pode facilitar a construção de uma proposta de Educação Permanente em Saúde é o fato de estarmos num ambiente de trabalho onde há muitos desafios e mudanças constantes, o que torna as pessoas, induz os funcionários a procurarem aprender mais na sua área de trabalho. (N1)

O fato acima coaduna-se com a proposta de EPS de aprendizagem-trabalho, uma vez que acontece a partir do cotidiano das pessoas e das organizações. ${ }^{5}$ Para tanto, surge a partir dos problemas enfrentados na realidade de conhecimentos e experiências dos sujeitos e das necessidades sentidas e evidenciadas na consecução de suas atribuições. E4 salienta que um fator facilitador para o desenvolvimento da EPS está na

[...] disponibilidade dos enfermeiros em realizar e participar de treinamentos, tanto para o seu próprio aproveitamento quanto ao de sua equipe. (E4)

A segunda subcategoria refere-se à oferta de cursos 'extras institucionais', na qual se visualiza a educação como um processo que propicia novos conhecimentos, capacita os funcionários para a execução adequada do trabalho e, prepara-os para futuras oportunidades de ascensão profissional, objetivando tanto o crescimento profissional quanto o pessoal. Sobre o fato, diz P1 que a educação está atrelada às

exigências por parte do governo [filantropia], da importância desta para a área da Saúde, e a evolução constante dos procedimentos em saúde. (P1) 


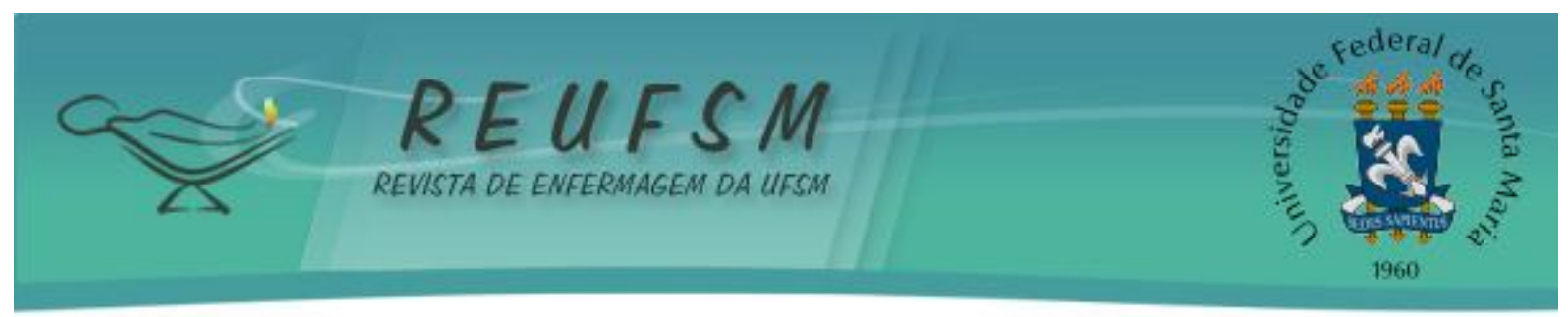

[Para a respondente] a oferta de cursos deveria ser em períodos fora do horário de trabalho [finais de semana] que sejam financiados pelo Ministério da Saúde como forma de estimular o funcionário público ou privado destinados aos cuidados do SUS a se atualizarem. Em contrapartida a exigência desses cursos gratuitos para que o aluno se empenhe através de avaliações sérias. (F1)

A participação da equipe multiprofissional em programas externos à instituição demonstra a importância atribuída pelos profissionais quanto ao seu aperfeiçoamento e o aprimoramento da assistência junto à equipe e, consequentemente, a qualificação da atenção aos usuários. A interação extra-instituição permite trocas de experiências teóricas e práticas com outros profissionais. ${ }^{13}$

Os fatores limitadores na construção de uma proposta de educação permanente em saúde

A segunda categoria refere-se aos fatores limitadores para a construção de uma proposta de EPS no espaço de trabalho. Muitas vezes a adesão dos funcionários aos programas educativos resvala em situações relativas ao

[...] cansaço físico. (E1)

[...] disponibilidade de horários, devido muitos funcionários possuírem mais de um emprego, fazendo que não tenha participaçãa de todos. (E2)

[um dos fatores limitadores está na] [...] resistência de alguns funcionários quanto ao novo e, na impossibilidade de mudanças devido a vícios antigos, também vejo certa dificuldade quanto à equipe médica em aderir à educação permanente. (E4)

A restrição em participar das ações educativas está relacionada à

falta de tempo, incentivos financeiros e, excessivas demandas de tarefas. (N1)

[O dilema está na situação em que] se fizermos um trabalho de educação permanente no horário de trabalho, talvez deixem de lado algo importante a ser feito naquele dia e se fizermos fora do horário de trabalhos pode ser que muitas pessoas não venham. (N1)

De forma assemelhada F1, M2 e P1 referem-se à falta de incentivo dos gestores dos serviços para que o trabalhador se atualize. Em algumas organizações a educação dos trabalhadores fica relegada a um plano secundário. Este fato decorre de inúmeros fatores: formas de organização do processo de trabalho; estruturação dos serviços; definição quantitativa de pessoal aquém das necessidades em decorrência da própria crise do setor, fazendo com que muitos trabalhadores tenham jornada dupla e, também, a falta de opções educativas e a distância de grandes centros educadores. Para M1 a limitação encontra-se no 


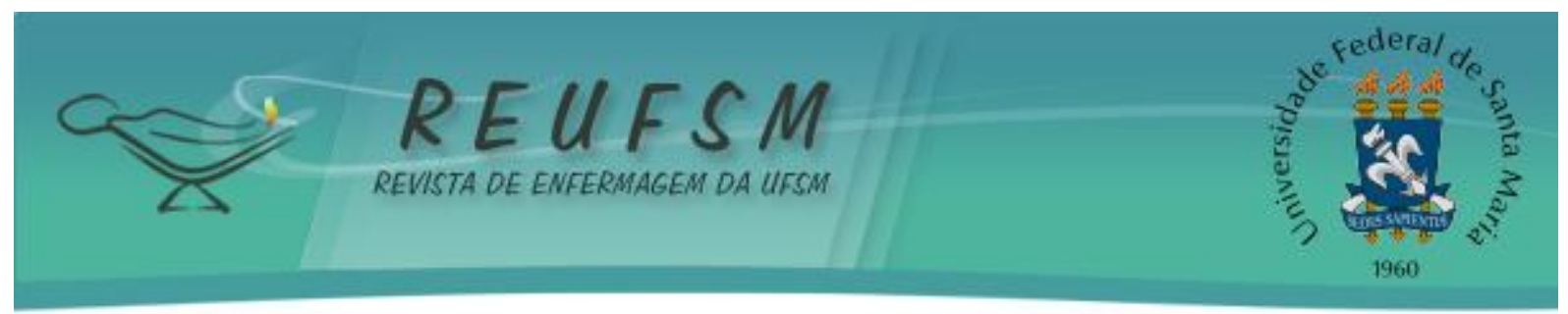

[...] pouco comprometimento da parte dos profissionais que atuam no setor com os resultados de âmbito coletivo. Na maioria das vezes, por ações voluntárias, isoladas, como resultado da ânsia individual, ou de pequeno grupo, de melhorar, adequar uma atividade mais resolutiva e procedente. (M1)

As instituições de saúde precisam organizar-se para acompanhar a evolução, traçando estratégias que irão orientar o caminho a ser seguido. ${ }^{14}$ Esse fator relaciona-se à

[...] falta de tempo para a educação permanente, remuneração profissional inadequada, falta de incentivos pelo hospital e a longa distância dos grandes centros educadores. (M2)

[...] crise financeira na área da Saúde, jornada de trabalho [que é dupla] de muitos trabalhadores da saúde e à dificuldade financeira que torna difícil investir em treinamentos. (P1)

Pode-se considerar factual que a distância dos grandes centros possa ser um fator limitador, assim como entraves de ordem econômica-financeira das instituições, duplas jornadas, entre outros. Esses e outros fatores precisam ser superados, utilizando-se de estratégias diferenciadas de educação. Em se tratando de educação permanente, sua acepção em si, procura transcender ao lugar comum de espaço, tempo, formas e conteúdos, preconizando que o local de trabalho seja o ponto de partida para o processo educativo.

\section{A organização de uma proposta de educação permanente em saúde}

A terceira categoria refere-se à organização de uma proposta de EPS de âmbito institucional. Esta categoria foi dividida em duas subcategorias: a primeira, referente à 'qualificação dos trabalhadores'; a segunda, ao 'contexto institucional de Educação Permanente em Saúde’.

A primeira subcategoria está relacionada ao processo de EPS como estratégia para qualificar os serviços. Sobre essa questão E1 diz que

[...] nos tempos atuais, o profissional deve qualificar-se no campo de trabalho, pois no trabalho a qualidade é cada vez mais exigida. (E1)

A EPS deve fazer parte do pensar e fazer da equipe, com o propósito de gerar interação entre os profissionais, crescimento pessoal e profissional de toda a equipe, impulsionando constantes melhorias no atendimento e no trabalho em equipe. E4 acredita que a EPS deva ser realizada também no

cotidiano da instituição e em treinamentos e reuniões periódicas, seguindo um cronograma, pré-agendado, e conforme surgirem dificuldades que o enfermeiro veja a necessidade de aprimorar seus conhecimentos e dos seus colaboradores. (E4)

$\mathrm{Na}$ perspectiva da EPS, aproximar a educação do cotidiano dos sujeitos é potencialmente conveniente, visto que esse ambiente é também um espaço de aprendizado, onde as ações diárias e as situações vivenciadas, quando analisadas de forma 


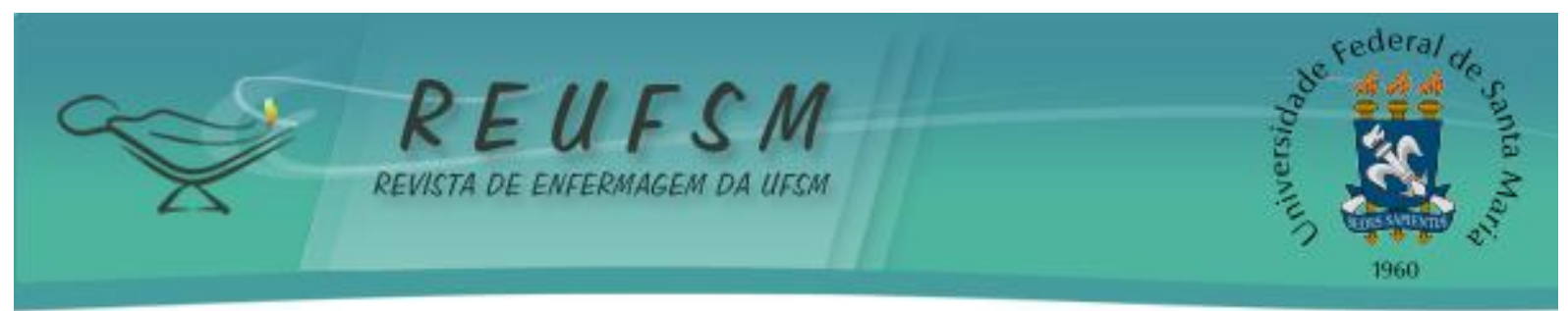

crítica e reflexiva, constituem-se em maneiras de valorizar o processo de trabalho. 0 ingresso ou a transformação de uma prática organizativa nos serviços de saúde sugere em não apenas trabalhar no desenvolvimento de novas habilidades específicas, mas, sobretudo, nos contextos que mantêm e alimentam as práticas. ${ }^{15-16}$

A EPS é uma prática educativa que ocorre no local de trabalho, facilitando assim a participação de todos os profissionais da instituição e proporcionando a interação entre eles. ${ }^{6}$ E2 salienta que para que se possa ter

profissionais qualificados, deve-se ter, em âmbito institucional a Educação Permanente para 100\% dos profissionais. (E2)

A EPS refere-se a ações educativas no trabalho, pelo trabalho e para o trabalho nos diferentes serviços, cuja finalidade é melhorar a saúde da população. ${ }^{17}$ E3 considera que a educação permanente se efetiva.

[a educação permanente se efetiva] através de educação, capacitações com as equipes, visualização do que é certo ou errado junto à equipe. (E3)

E1 reforça que

[a qualificação pode ser obtida] através de algumas capacitações. O que falta para o funcionário é que se tenha um plano de carreira para haver um estimulo em buscar a educação permanente em saúde. (E1)

Na segunda subcategoria aborda-se a EPS no contexto institucional. Considerando que a educação permanente é a realização do encontro entre o mundo de formação e o mundo do trabalho, na qual o conhecimento teórico incide sobre o prático e estes repercutem no processo de trabalho, AS1 assevera que a

[...] busca pela aprendizagem estará promovendo a mudança das praticas profissionais. As instituições procuram trazer para a realidade a esfera de trabalho versus formação, onde o aprender $e$ o ensinar, teoria e prática, se coligam no cotidiano das instituições e ao trabalho, e, sem dúvida, a busca incondicional pelo aprender a aprender a profissão torna-se incessante nos dias atuais. (AS1)

[...] são poucas as instituições que trabalham a educação permanente em saúde. (N1)

[...] [deveria ter] cursos mais complexos partem somente do interesse do funcionário, que se capacita e, na maioria das vezes, não vê retorno financeiro e tem gastos altos para se capacitar. (F1)

A participação dos trabalhadores nas atividades concernentes à EPS, na visão de M1, está atrelada a 


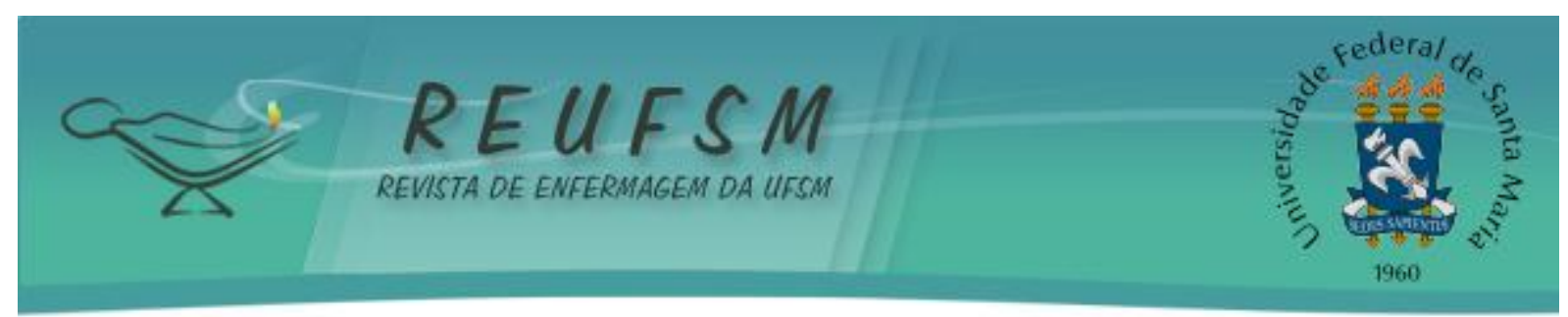

ações voluntárias, isoladas, como resultado da ânsia individual ou de pequeno grupo, de melhorar, adequar uma atividade mais resolutiva e procedente. (M1)

É a partir da problematização do processo e da qualidade/resolutividade do trabalho em cada setor que são identificadas as necessidades de educação; sendo assim, o processo de EPS constitui-se em uma importante estratégia de qualificação dos serviços, na qual os sujeitos trabalhadores veem-se mais envolvidos, interessados e participativos, valorizando o conhecimento e, consequentemente, aumentando as oportunidades de aprendizagem em seu próprio local de trabalho. ${ }^{3}$

[...] o processo de envolvimento da enfermagem na educação é significativa, pois envolve todas as áreas do hospital. (M2)

O enfoque da EPS representa uma importante mudança na concepção e nas práticas de capacitação dos trabalhadores dos serviços de saúde, incorporando o ensino e aprendizado à vida cotidiana das organizações e às práticas sociais, no contexto real em que ocorrem, modificando assim as estratégias educativas, a partir da prática como fonte de conhecimento e de problemas. ${ }^{18}$

Teoricamente, a política nacional de Educação Permanente em Saúde é voltada para a formação e desenvolvimento dos trabalhadores do SUS. Prega a descentralização e regionalização do sistema, por meio de repasses do Fundo Nacional de Saúde aos respectivos Fundos Estaduais e Municipais de Saúde. Institui que o desenvolvimento da função de gestão da educação na saúde é uma responsabilidade tripartite, assim o que vemos na realidade, principalmente no nível municipal, é a dificuldade em estender ao hospital as possíveis capacitações realizadas. Também, por ficarmos no interior, temos dificuldades financeiras e de inscrição para participar dos cursos na capital. (P1)

Na proposta da educação permanente, a mudança das estratégias de organização e do exercício da atenção é construída na prática das equipes. ${ }^{18}$ As questões para as capacitações não devem se resumir apenas a uma lista de necessidades individuais de atualização, mas sim a partir da origem dos problemas que acontecem nos respectivos espaços em que ocorre a atenção à saúde e à organização do trabalho, considerando sempre a necessidade de realizar ações e serviços relevantes e a qualidade da assistência prestada.

Para M2, a educação médica na instituição pesquisada consiste em "reuniões científicas encabeçadas pelo clube do médico ou por uma cooperativa médica", em que são definidos os assuntos de maior interesse dos médicos do corpo clínico do hospital e de toda região. Para eles, as reuniões científicas do corpo clínico deste hospital estão "hoje bastante escassas". Estas, normalmente estão vinculadas a realização de protocolos médicos nas mais diversas áreas da medicina, "Terapia Intensiva, clínicas, cirúrgicas e obstétricas".

A gestão de pessoas nos serviços de saúde implica em benefícios estruturais, organizacionais e pessoais. No contexto das organizações de saúde, as contribuições advindas do aperfeiçoamento dos modelos de gestão estão vinculadas a melhorias na qualidade dos serviços. ${ }^{19}$ Com isso, pode-se dizer que a educação permanente requeira ações no âmbito da equipe multiprofissional, para que as formas de organização do 


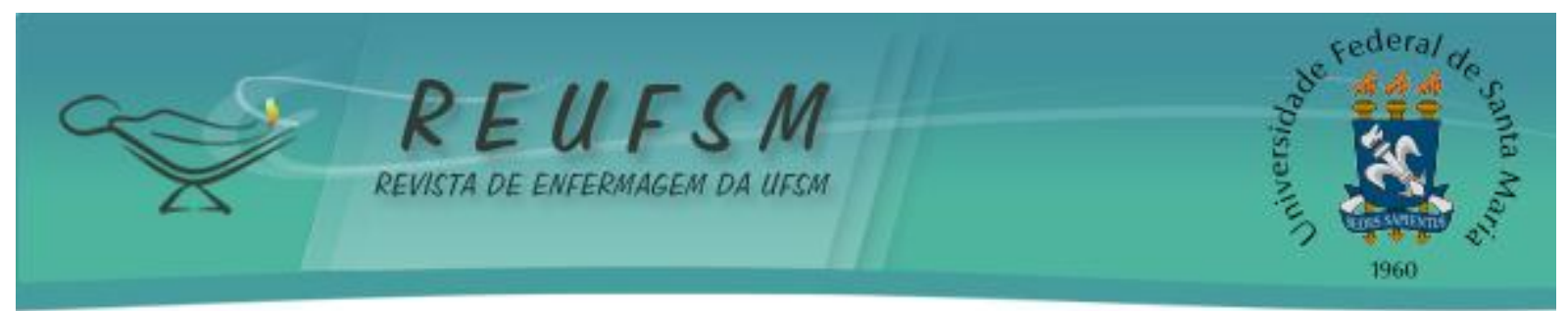

trabalho, possam se integrar com as redes de gestão dos serviços de saúde, assim como, permitir a efetiva participação do controle social.

Considerando a variedade das necessidades de desenvolvimento pessoal/profissional, a EPS pode constituir-se em uma importante estratégia para que os sujeitos, entendidos aqui como educandos e educadores, aprimorem sua capacidade de articularem as mudanças, oportunizando assim, trocar experiências, a socialização e a construção coletiva de uma cultura organizacional de aprendizagem no exercício do trabalho.

\section{CONSIDERAÇÕES FINAIS}

Os desafios na construção de uma proposta de EPS necessitam transcender a alguns quesitos sejam estes de ordem organizacional ou cultural. Nas instituições, os gestores precisam compreender que a educação em saúde não é apenas um apêndice e, por isso mesmo, precisa ser tratada como uma estratégia permanente de desenvolvimento pessoal e, consequentemente, organizacional. Para tanto, carece em conceber e executar um plano pedagógico institucional de educação em saúde. No quesito cultural, necessita-se entender que os treinamentos e capacitações não são finalizadores, estes são tão somente pontos de partida para um processo educativo amplo e, que busque o desenvolvimento integral dos sujeitos. 0 preceito da EPS vincula-se com o desenvolvimento integrativo dos sujeitos, em virtude de que se utiliza de pressupostos como a inclusão do pensar e refletir sobre as relações que se estabelecem entre o saber e o fazer.

Sendo a proposta de EPS uma estratégia para a transformação profissional, podese dizer que esta ocorre através da articulação entre a teoria e a prática realizada entre os sujeitos-trabalhadores, agregada a política institucional a que fazem parte. Com isso, presume-se que as mudanças que ocorrem no local de trabalho possam vir a se confrontar com o instituído, pois dentre os desafios que limitam a implementação de uma proposta de EPS está a falta de incentivo por parte dos gestores da instituição e, também, a não valorização do processo educativo pelos coordenadores.

Embora toda a tecnologia educativa existente facilite o aprendizado, considera-se ainda que a distância de grandes centros de educação tende a prejudicar a atualização do profissional. Contudo, salienta-se que o estabelecimento de uma política interna de educação no trabalho, seja umas das formas de superar estes desafios. A liberação de trabalhadores em eventos científicos, com a posterior replicação dos conhecimentos adquiridos é uma das formas de superação as distâncias.

Outros limites, a serem superados relacionam-se a estruturação dos serviços, a definição quantitativa de pessoal e principalmente, desenvolver institucionalmente uma cultura de educação no trabalho. Porquanto, uns dos mais sérios desafios a serem superados constam da cultura de que o processo educativo necessite de espaços/momentos e conteúdos pré-definidos. A ação educativa é dinâmica e pode ser desenvolvida em qualquer momento e local, conforme a necessidade sentida, isto é, a problematização referente ao cotidiano de trabalho serve de subsídios para estabelecer o processo educativo. Assim, no espaço de trabalho, o processo de trabalho passa a ancorar-se no trinômio 'gestão-educaçãoatenção'. Nesse modo de projetar os processos educativos, necessita-se de ações que facilitem a intersecção dos preceitos teóricos, com os problemas nas práticas do cotidiano, na qual o fazer educativo são mais efetivos, quando mediados pelo diálogo.

Apesar de todas as dificuldades enfrentadas por ser um hospital de interior, os coordenadores mostram que não medem esforços para manter suas equipes atualizadas, sempre que possível promovem encontros para capacitar suas equipes. Embora, ainda que recente, a política de educação permanente encontra como principais entraves: o distanciamento entre as coordenadorias de saúde e as instituições de ensino e instituições 


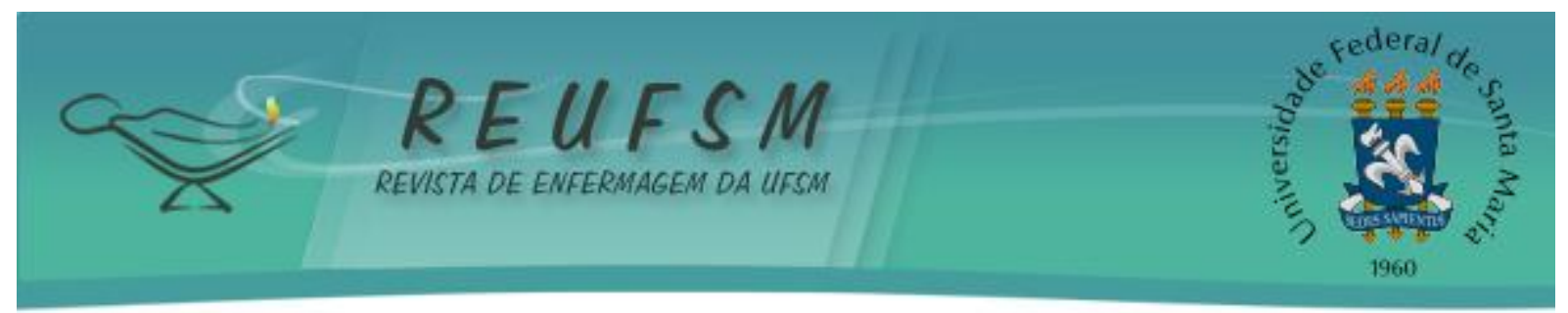

de saúde, a excessiva burocratização na elaboração dos projetos que precisam transitar em inúmeras instâncias e diferentes trâmites.

Também há desconhecimento por parte dos gestores das instituições de saúde das possibilidades de estabelecerem-se parcerias entre as coordenadorias, universidades e serviços. Na instituição na qual foi realizada a pesquisa, observa-se a necessidade premente de buscar parcerias com instituições extra-hospitalares, para suprir necessidades internas de ações educativas inovadoras que possam ancorar transformações destinadas a qualificação dos trabalhadores e, o consequente aprimoramento da assistência aos usuários. Também revela o estudo, que a EPS enquanto política de estado e a utilização de seus preceitos, ainda não adentraram nessa instituição hospitalar.

\section{REFERÊNCIAS}

1. Silva LAA, Backes VMS. Perspectivas de transcender na educação no trabalho: tendências da enfermagem latina americana [tese]. Florianópolis (SC): Universidade Federal de Santa Catarina, Programa de Pós- Graduação em Enfermagem; 2007.

2. Paschoal AS, Mantovani, Méier MJ. Percepção da educação permanente, continuada e em serviço para enfermeiros de um hospital de ensino. Rev Esc Enferm USP. 2007; 41(3):478-84.

3. Carotta F, Kawamura D, Salazar J. Educação permanente em saúde: uma estratégia de gestão para pensar, refletir e construir práticas educativas e processos de trabalho. Saúde Soc. 2009;18 Supl 1:48-51.

4. Ministério da Saúde (BR). Secretaria de Gestão do Trabalho e da Educação na Saúde. Departamento de Gestão da Educação em Saúde. A educação permanente entra na roda: pólos de educação permanente em saúde: conceitos e caminhos a percorrer. Brasília (DF): Ministério da Saúde; 2004.

5. Ministério da Saúde (BR). Secretaria de Gestão do Trabalho e da Educação na Saúde. Departamento de Gestão da Educação na Saúde. A educação permanente entra na roda: pólos de educação permanente em saúde: conceitos e caminhos a percorrer. Brasília (DF): Ministério da Saúde; 2005.

6. Ricaldoni CAC, Sena RR. Educação permanente: uma ferramenta para pensar e agir no trabalho de enfermagem. Rev Latinoam Enferm. 2006 nov-dez;14(6):837-42.

7. Murofuse NT, Rizzotto MLF, Muzzolon ABF, Nicola AL. Diagnóstico da situação dos trabalhadores em saúde e o processo de formação no polo regional de educação permanente em saúde. Rev Latinoam Enferm. 2009;17(3):314-20.

8. Gil AC. Métodos e técnicas de pesquisa social. São Paulo: Atlas; 2007.

9. Triviños ANS. Introdução à pesquisa em ciências sociais: a pesquisa qualitativa em educação. São Paulo: Atlas; 1987.

10. Turato ER. Tratado da metodologia da pesquisa clínico-qualitativa. Petrópolis: Vozes; 2003.

11. Conselho Nacional de Saúde (BR). Resolução n. 196/96: dispõe sobre pesquisa envolvendo seres humanos. Brasília (DF). 1996. out; (4):15-25.

12. Minayo MCS. O desafio do conhecimento: pesquisa qualitativa em saúde. São Paulo: Hucitec; 2004. 


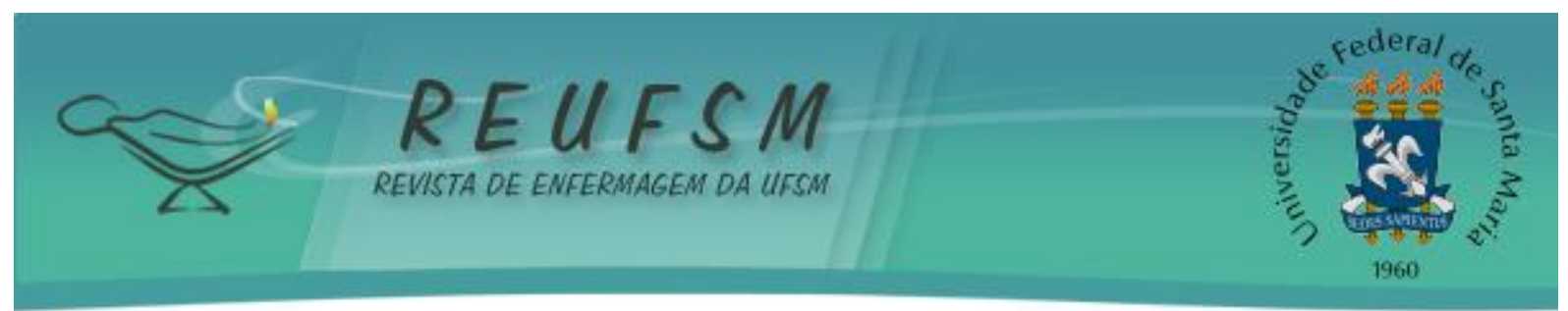

13. Wendhausen ÁLP, Saupe R. Os desdobramentos da promoção da saúde na realidade Latino-americano/Brasileira: participação, empoderamento e interdisciplinaridade. In: Saupe R, Wendhausen ÁLP, organizadores. Interdisciplinaridade e saúde. Itajaí (SC): Universidade do Vale do Itajaí; 2007. p. 117-40.

14. Siqueira $\mathrm{HCH}$. As interconexões do serviço no trabalho hospitalar - um modo de pensar e agir [tese]. Florianópolis (SC): Universidade Federal de Santa Catarina; 2001.

15. Ministério da Saúde (BR). Secretaria de Gestão do Trabalho e da Educação na Saúde. Departamento de Gestão da Educação em Saúde. Portaria GM/MS nº 1.996. Brasília (DF): Mistério da Saúde; 2007.

16. Ministério da Saúde (BR). Secretaria de Gestão do Trabalho e da Educação na Saúde. Departamento de Gestão da Educação em Saúde. Política nacional de educação permanente em saúde. Brasília: Ministério da Saúde; 2009.

17. Davini MC. Enfoques, problemas e perspectivas na educação permanente dos recursos humanos de saúde. Política nacional de educação permanente em saúde. Brasília (DF): Ministério da Saúde; 2009. p. 39-59. (Série Pacto pela saúde; vol. 9).

18. Ministério da Saúde (BR). Política de educação e desenvolvimento para o SUS: caminhos para a educação permanente em saúde: pólos de educação permanente em saúde. Brasília (DF): Ministério da Saúde; 2004.

19. Furukawa PO, Cunha ICKO. Da gestão por competências às competências gerenciais do enfermeiro. Rev Bras Enferm. 2010;63(6):1061-6.

Data de recebimento: 04/05/2012

Data de aceite: 19/07/2012

Contato com autor responsável: Luiz Anildo Anacleto da Silva

Endereço: Antonio Boenig, 268, Bairro Morada do Sol, ljuí-RS.

CEP: $98700-000$

E-mail: luiz.anildo@yahoo.com.br, luiz.anido@smail.ufsm.br 